\title{
13 Comparative Political Thought
}

\author{
Brooke Ackerly and Rochana Bajpai
}

\section{$1 \quad$ Introduction}

Two features characterize the emerging field of comparative political thought (CPT). The first is an interest in bringing Islamic, Indian, Chinese, African and Latin American ethical-political thought to the attention of Western audiences. The second is an interest in combining the methods of political theorists with those of historians, political scientists and anthropologists to enhance real-world relevance of political theory. This chapter provides an overview of normative-analytic, historical, interpretive and critical approaches to CPT with examples of variants within each category. It argues for a methodology-based definition of CPT, and for a non-hierarchical pluralism in which multiple vocations of political theory prevail. Recognizing the complexity of questions raised by the topic of methods in political theory generally, our aims in this chapter are first to provide an introduction to CPT, second to provide a schematic of the four methodological strands within CPT and finally to highlight the range of methods useful for CPT research, and, where these have something in common with other practices of political theory, to elaborate on how they are used in CPT. To underline, this is an argument about the variety of methodologies and methods in CPT scholarship and an appreciation of the value of this methodological pluralism for the field overall.

Political theorists have been comparing across time, authors and contexts since the field began. In the twenty-first century, given the contributions of post-colonial, feminist and queer scholars, we would expect most political theorists to attempt to be self-aware regarding the parochialism and historical elitism of some political theory. However, today, the phrase 'comparative political thought' indicates to an Anglophone audience a way to teach and practise political theory that is less Western-centric. Obviously, non-Western-centric approaches to political thought have long featured in teaching and writing in Asia, Africa, the Middle East and Latin America. Today, the phrase 'comparative political thought' is 
used to characterize political theory within the Anglo-American academy that uses methods that challenge Euro-American parochialism. The difference between contemporary CPT and cross-cultural, crosslanguage and cross-time comparisons of previous generations may be its self-reflective attempts to define the field and methods of CPT.

Early progenitors of CPT sought to emphasize cultural differences and incomparability. For example, British colonizers engaged with political elites in South Asia and China to interpret local political theory and cultural practice in ways that facilitated the political economy of colonial rule. The post-World War II project of identifying the universal human rights that provided the anchor commitments of the United Nations, however, sought to identify universal values that transcended cultural differences. In the post-Cold War era, the breakup of the former Yugoslavia and multinational communist regimes, the transformations in the political economies of East Asia, the ongoing tensions in the Middle East and the influence of Islamist political thought has led to the demand for political theory that does not serve imperial ends and is open to universal dimensions of humanity and yet treats differences as strengths.

Contemporary CPT reflects the incorporation within mainstream political theory of the influences of anti-colonial, anti-racist and feminist political theory (see also Gordon 2014). ${ }^{1}$ The groundwork for the selfreflective turn in political theory embodied in CPT was laid by their criticisms of imperial and patriarchal ideologies. In particular, postcolonial and feminist criticisms of hierarchal notions of difference on the one hand, and false universalisms on the other, represented one of the profound contributions to political theory. CPT reflects a broadening of the range of intellectual resources being brought to bear on these critiques beyond the Euro-American core of political theory. It represents the motivation to develop theories and methods grounded in the historical traditions and contemporary practices of non-Western societies that transcend the frameworks of area studies, and at the same time, are not dominated by liberal theories.

How do we determine which intellectual traditions should inform contemporary comparative reflections? Should we dialogue between or among such traditions? Do we need to study multiple languages in order to participate in such dialogues? Or do we need language fluency along with deep ethnographic and historical understanding of a particular unknown conceptual terrain in order to shed light on new problems?

${ }^{1}$ Compare this account of the history of the field with those of Freeden (2007), Godrej (2011) and Von Vacano (2015). On the parallels between Orientalist scholarship, and comparative political theory in terms of seeking to articulate the value of non-Western scholarship for Western knowledge, see Thomas (2010). 
Or, does CPT require engagement with contemporary scholars who have training, experience and imaginations developed in multiple traditions? As all of these questions suggest, many scholars today feel the need to broaden the tool-kit of political theory to include not only new languages, but also new ways of thinking about the historical epistemology of concepts. These are questions about methods.

CPT scholars use a range of methods and answer these questions differently. Methods choices depend on the researcher's ontology, epistemology and methodology. Ontology is the worldview that determines what the theorist finds to be an interesting question; epistemology is the theoretical distinction between fact and opinion and is behind a theorist's choice of methodology; methodology is the theory of how research should proceed. Methods are the specific techniques or tools for carrying out the research (Ackerly and True 2010: 9-10; 2012). Certain methods - for example the close reading of historical texts - are used by all methodologies of CPT. However, these methods are used differently depending on the specific research question and overarching methodology of the project.

In order to discuss the methodologies and methods of CPT, we have to engage, but not embrace, two suspect premises: that the field of comparative political thought is a subdiscipline with distinct methods and that delimiting those methods strengthens the field. Perhaps because comparative political thought is a relatively new field in political theory, most participants in the field have spent significant time being explicit about and defending their methods. Michael Freeden refers to 'the absence of considered approaches, and their attendant methodologies' of CPT as 'one of the great lacunae in the study of political thinking' (2007: 1). For many political theorists, explaining and defending our choice of and use of chosen methods is part of justifying our arguments (Herzog 1985; Gaus 1990; Forst 2001). We believe that a discussion of methodologies is useful in order to clarify the choices available and to defend the intellectual case for all of the methods in the field. What the field needs now is a pluralist account of those methodologies so that rather than debating which methods and approaches the field should privilege, we can build an inclusive field whose methodological attentions focus on the importance of (1) choosing the approach or approaches appropriate to the particular question at hand and (2) doing that approach well.

In this chapter we discuss a range of normative, historical, interpretive and critical approaches to comparative political thought. Not all of those who participate in the field use all of these approaches, and some CPT scholars would not recognize certain approaches as being appropriately 
understood as part of the field. However, we have taken a pluralist understanding of the field and thus review a broad range and their methodological implications. To prescribe how comparative political thought should be done from the standpoint of one particular methodology or method is to truncate prematurely the scope of this emerging field. In this sense, our view of CPT is critical of non-pluralist approaches; however, we treat these approaches, like the others, as offering resources for studying certain questions.

\section{What Is Comparative Political Thought?}

The defining aim of comparative political thought has been to foster greater engagement with non-Western thought within mainstream political theory. The reasons for studying political thought in the Middle East, Asia, Africa and Latin America of course differ among CPT scholars. A secondary aim has been to enhance the lived-world relevance of political theory, in many cases through combining the methods of political theorists with those of political scientists, historians, anthropologists and other empirical disciplines. In their early work in CPT, Fred Dallmayr and Roxanne Euben engaged with both strands. For Dallmayr, political theorists were late in responding to the issues raised by Islamic extremism and globalization, because they neglected realworld political processes in their preoccupation with abstract theorybuilding (2004: 249). Euben noted that the boundaries between political theory and comparative politics were arbitrary (1999: 159).

The first aim raises a challenging set of questions: is a focus on nonWestern thought sufficient to characterize a study as 'comparative political thought', or does it need to fulfil additional criteria to qualify as comparative inquiry, as some have argued (Freeden 2007; March 2009)? There has been a long history of centralizing the Western canon, and also of the post-colonial critique of Eurocentrism within political theory. Does bringing texts from Asia, Africa and Latin America into the canon then suffice for comparative inquiry in political thought? In this vein of reflection, the use of the label 'comparative political thought' simply as an account of a thinker's geographical location, independent of whether comparison in a substantive sense is engaged, appears to ghettoize nonWestern political thought (March 2009).

The second aim raises another set of questions for CPT. If the primary definition of comparative political thought is methodological, in terms of combining methods of political theory and comparative politics for instance, is the study of non-Western political thought necessary for the definition of the field? In other words, does the 
significance of the method of comparison mean that we should drop the initial emphasis on non-Western texts as a defining feature of comparative political theory, while still recognizing that it has great value (just as some comparisons in political science are more instructive than others)? In this vein, studies that compare political thought across Western countries, for instance, would qualify as exercises in comparative political thought, as is the case in sub-disciplines like comparative literature or comparative religion (Freeden 2007; GotoJones 2011), as would single-country comparisons of different cases (Bajpai 2011). In interpretive and critical approaches discussed later, the initial aim of CPT of engaging with marginalized bodies of political thought takes the form of a focus less on non-Western sources than on non-elite texts and action, usually the subject of comparative politics, as the 'texts' of political theory.

To what extent should we think of both regional and comparative methods approaches to CPT as part of the same enterprise? We argue that these are both essential parts of the field. To deny the first is to divorce CPT from its animating impulse that remains relevant, that of challenging the marginalization of non-Western forms of knowledge production and transmission (Godrej 2011: 14) and potentially transforming the repertoire of concepts and methods in Western political theory (Jenco 2007). To deny the second is to ignore the pitfalls of a disciplinary division of labour between political theory and political science (e.g. Freeden 2007), as well as the politics of disciplinary boundary policing and crossing, that have always been a part of political theory as well (e.g. Wolin 1969).

The methodological meaning of the 'comparative' in CPT - the joining up the methods of political theorists and comparative analysts - is equally central to intellectual engagement with marginalized bodies of thought. In our view, the comparative enterprise seeks to challenge dominant ideologies and epistemologies and therefore cannot rely only on traditional textual resources. As such, it becomes part of the role of CPT to reflect on methodologies in political theory and the epistemological and ontological power dynamics these exhibit.

Within CPT, political theory has been construed broadly, to include analytical political philosophy (sometimes called 'normative' theory), history of political thought, critical theory and interpretation, the study of political ideologies and discourse analysis (Freeden 2007; March 2009). Constructing normative arguments about what it is right to pursue, advancing understanding of thinkers, texts and traditions, as well as enhancing explanations of political phenomena, all count as 
political theory inasmuch as they focus on concepts and arguments that are at the heart of political theory.

Like political theory, comparison too is construed widely in comparative political thought, across differences of space as well as time. Most broadly, political theory has been comparative since the time of Aristotle; indeed, some have argued that political theory is inherently comparative (Euben 1999; Freeden and Vincent 2013). Most narrowly, CPT might compare cultural difference between Western and non-Western thought (March 2009). However, as noted earlier, whether comparison across a Western/non-Western difference is a necessary criterion for comparative political thought is a matter of continuing debate in the field.

CPT destabilizes familiar references points within political theory. CPT questions can be disruptive and 'decolonizing' (e.g. Chan 2009; Mills 2015), seeking to displace the hegemony of Western categories and methods (Jenco 2007; Godrej 2011). They can also be transformative and constructive (e.g. Jenco 2011; Kim 2014). And CPT can be conversational or discursive, seeking to exchange insights and build new insights (e.g. Dallmayr 1999; Angle 2002; Ackerly 2005; Bajpai 2011). Some CPT scholars, trained in Western thought, have no training in the languages and political thought traditions outside of the West and have been working outside of their comfort zone for intellectual and pedagogical reasons. There are others - often academics from non-Western traditions - for whom academic training in political thought has always been cross-contextual. And there are others who have trained in one tradition but later develop research interests that require another tradition and extensive language training. Hence, the practice of CPT reflects a range of methodologies.

\section{How Do We Do CPT? Four Methodological Approaches}

CPT is like a family tree, with participants utilizing a broad range of methodologies drawing on a complex root system constructed out of a range of political and intellectual struggles. As the field has developed, sometimes rigorous defence of the appropriateness of one's methodology has meant privileging a particular approach. In contrast, our aim is not so much to argue for the superiority of a particular approach, but to highlight the diversity of methodologies and purposes in the field.

We distinguish four principal modes of doing CPT for heuristic purposes: normative-analytic, historical, interpretive and critical. Our intention is not to reproduce conventional disciplinary categories, but to show how these have been configured and challenged in CPT scholarship. Within each methodology, there are of course multiple practices. 
In our discussion, we nuance our categorization with specific examples. Individual theorists often work in more than one mode: theorists may emphasize one methodology in one work and another approach in another work, or, indeed use multiple methodologies in a single study. Thus, our classification does not seek to label scholars, but rather to identify the diversity of methodologies that have constituted the field of $\mathrm{CPT}$, and to suggest exemplary instances of each.

Distinguishing between these approaches is important for at least two reasons. First, it gives those interested in turning to CPT a sense of how to draw on their own individual strengths in political theory to become more comparative in their scholarship. Second, in the field of political theory, critical and interpretive social science approaches are often misrecognized as normative and historical approaches, respectively. We argue that these are qualitatively distinct in their epistemological and methodological implications. Interpretive social scientific and critical methodologies act in part as a check on the epistemological power of normative-analytic and historical methodologies in the field of political theory.

\subsection{Normative-Analytic CPT}

The first category is of CPT as a form of or as an aid to building normative-analytic theory. One strand among normative-analytic approaches is a response to the criticism that political philosophers have been insufficiently attentive to the empirical conditions needed for their recommendations to be translated into reality (see also the chapters by Jubb and by Schmidtz in this volume). CPT in this vein attempts to construct normative arguments that are sensitive to the gap between 'ideal principles and social reality' and seek to 'find a way to connect facts and norms, practical reforms and substantive ideals' (Laborde 2008: 13) (cf. Chan 2009: 5). Among scholars of non-Western political thought, normative-analytic methods are to be found in studies that compare familiar Western principles such as democracy, rule of law and human rights with the intellectual resources of non-Western traditions such as Confucianism (e.g. Ackerly 2005), or use Western terms of political philosophy - such as 'ideal' and 'non-ideal' theory - when studying non-Western traditions (see Chan 2009: Introduction; Kim 2014: chapter 1).

By way of illustration, Stephen Angle (2005) elaborates and juxtaposes the normative resources for democratic centralism in Rawls's notion of a decent society on the one hand, and in Chinese thought, on the other. His motivation is not only to find 'grounds for mutual respect' (Angle 2005: 
540), but also to further the cause of practical reforms in contemporary China. Importantly, although the desired direction is of democratizing reform, Western liberal democracy is not posited as the desired end-state in Angle's account. Instead, the comparative reconstruction of the Rawlsian notion of a decent society and of Chinese ideas of democratic centralism in conversation with each other allows for the elaboration of alternative ideals that are distinct from traditional liberal democracy (and also from Chinese practice), and crucially, that can be accepted as legitimate by those engaged in Chinese politics. In a similar vein but with different conclusions, Daniel Bell (2000) offers controversial proposals for a democratic regime based on traditional Confucianism of rule by 'a capable and public-spirited "Confucian" intellectual elite'. Like Angle, Bell affirms 'the importance of local knowledge of cultural traditions' not only 'from the standpoint of their efficacy, but also from the point of view of revising political ideals themselves' (Bell 2000: 19, 14).

In these writings, both theorists draw on empirical knowledge of nonWestern societies and institutions and seek to construct normative arguments of real-world relevance in an analytic mode. Engagement with non-Western traditions serves in both cases to enlarge the repertoire of desirable ideals. Other work by these authors demonstrate a more explicitly interpretive and even critical CPT methodology - see, for instance, Bell (2008), Angle (2012) and Kim (2014).

The connection between ideal and non-ideal theory is common among normative approaches (see also Tan 2003), but it is not the only framing of normative-analytic CPT. Andrew March in some of his writings offers a combative statement in support of certain normative-analytic approaches to non-Western thought. March argues that the ultimate aim of CPT should be to evaluate moral conflicts between distinct traditions of thought: 'comparative political thought derives its greatest sanction from the cases of principled value conflicts which matter between more or less systematic and autonomous doctrinal systems', instantiated 'in its purest form by religious or other doctrinal truth claims' (March 2009: 34, 31). The turn to non-Western religions and philosophies here is animated by a specific motivation to identify areas of moral disagreement between relatively 'autonomous systems of argumentation', and most importantly to adjudicate in instances of moral conflict, to seek 'plausible grounds for consensus in other traditions' (March 2009: 38). This kind of normative comparative political thought, according to March, includes and subsumes what is valuable 'in the weaker form of comparative political thought, namely the "diagnostic" element of examining the contours of disagreement between traditions and the "appreciative" element of demonstrating the diversity of other traditions'. 
As a rejection of the term 'comparative political thought' simply as a proxy for non-Western political thought, and as a call for thinking seriously about why and what we should compare as political theorists, March (2009) offers a welcome perspective. As a prescription for how CPT should be done, however, there are reasons for caution. First, the approach treats different religious traditions as developed within selfreferential cultural systems. This was a feature of religious studies of the colonial era that has been debunked. March can respond by saying that his is a stylized account of religion and liberal democracy. Normativeanalytic theorists, as we know, often do rely on models that are not meant to be literal descriptions of society (well-known examples include the state of nature and the original position). Nevertheless, at the very least, this needs to be much more explicit in arguments involving religious traditions, given the role of intellectual, political and economic power in defining what religion is and who its followers are. Second, perhaps deriving from its choice of religious doctrines as the units of comparison, March's definition of CPT stipulates unnecessarily demanding criteria for comparison, notably that comparison should be between units that are more or less autonomous or mutually exclusive. This relies on an idealized model of comparison of distinct objects, which has long been deconstructed in the practice of comparative social and humanitiesoriented disciplines (literature, art, philosophy, religion and politics) that reject the separateness of the objects of comparison as artificial. Third, it is simply not the case that comparison in the normativeanalytic mode can subsume without remainder what is valuable in historical, critical and interpretive forms of political thought (Bajpai 2011). Normative-analytic theorists have typically wielded highly reified notions of tradition and culture, whereas the central thrust of historical, interpretive and critical approaches has been to demonstrate the internal complexity and diversity of unified wholes as well as the dialogical development of traditions, cultures and ideas. As such, while the construction of normative-analytic theory is undoubtedly one important purpose that a comparative political theorist might pursue, to elevate its requirements as the standard for all endeavour in the field is to limit the scope of CPT.

\subsection{Historical CPT}

Historical CPT is by far the most prevalent approach. It comprises impressive scholarship on key non-Western thinkers, schools of thought and traditions. We distinguish historical approaches not by the time periods of the studies (e.g. prior to 1945), but by their methodologies. Historians of non-Western political thought, like their counterparts 
working on European thought, have offered different answers to the question of how we ought to interpret historical texts from the nonWestern world, which kind of texts we should focus on, how we should define the appropriate context that is relevant for understanding texts and how the interpretations of past thinkers can instruct us about current intellectual and political problems.

What these diverse approaches share is that analysis is driven primarily by an interest in the recuperation or retrieval of lost or misunderstood meanings of concepts (e.g. jihad), thinkers (e.g. Islamists such as Qutb and Mawdudi) and traditions (e.g. Confucianism). Historical interpretation is of course informed by normative aims, and in some cases explanatory intentions, and we can see the family resemblance between certain normative and historical projects (Ackerly 2005). However, the central thrust of analysis undertaken is to foster greater appreciation of the intricacy and sophistication of non-Western thinkers, texts and traditions, and thereby to enrich and possibly transform the repertoire of political theory.

Historical approaches in CPT have advanced research methods in political theory in important respects. First, with regard to the sources of political thought, political theorists have conventionally focused on prestigious texts and great thinkers, whereas historians of ideas and theorists of ideology have highlighted the significance of more mundane sites of political thought - political pamphlets, propaganda pieces, politicians' speeches. Students of non-Western political thought have also suggested that an adequate appreciation of these traditions requires us to examine not just verbal knowledge articulated in texts and speech, but also knowledge that is implicit in non-verbal expressions of ritual, painting, music and dance (Jenco 2007), as historians of pre-modern periods have also emphasized. Indeed, games, graphics and new media technologies may 'hold expressive potentials for political ideas that a more “conventional" treatise cannot express' (Goto-Jones 2011: 107).

A second contribution of historical approaches relates to what the appropriate contexts are for comparative inquiry into non-Western thought. Theorists have offered two standpoints, one that emphasizes resemblance, and the other, difference. In the first case, scholars have located concepts and thinkers of non-Western thought in interpretive contexts familiar to students of Western political thought. This can involve, for instance, the recuperation of the histories of concepts such as democracy and civil society in Arab thought (Browers 2006), of secularism and liberal ideologies in India (Bajpai 2002, 2012). Roxanne Euben's work is a leading example of this strategy. In Enemy in the Mirror, she argues that 'Qutb is not a critic of modernity per se - for he views 
technologies and scientific achievements as desirable - but an opponent of post-Enlightenment rationalism.' She argues that the ethico-political worldview of Qutb and other Islamic fundamentalists is best understood when placed alongside Western critics of Enlightenment rationality such as Hannah Arendt, Charles Taylor and Alasdair MacIntyre (Euben 1999: 155). Reframing Islamist thought as substantively similar in its formulations to internal Western critics of modernity undermines popular stereotypes of Islamism as a foreign, extremist and archaic ideology, at the same time as serving to highlight currently marginal strands within Western political thought. More generally, the excavation of parallels between non-Western and Western thought undermines influential claims of a clash of civilizations between Islam and the West, or the 'West and the Rest'. A key challenge its practitioners face, however, is to mitigate the pitfalls of using Western conceptual frameworks for the reconstruction of non-Western thought, and thereby imposing Western categories and frames on non-Western traditions and practices (for a discussion of the pitfalls and how these can be mitigated, see Godrej 2011, chapter 2).

The second strategy addresses this risk by emphasizing difference. Some historians of non-Western thought have argued that global political theory requires us to work primarily from within the terms and approaches internal to non-European traditions, attempting to jettison, at least temporarily, the familiar categories of Western political theory. Leigh Jenco cogently articulates a case for deriving methods for the study of texts from within the scholarly traditions in which these are embedded (Jenco 2007: 745). Jenco points out that the 'frames of inquiry' of crosscultural theorists have remained 'beholden to modern Western epistemological debates' (2007: 745). Proper understanding of non-Western thought requires not just linguistic knowledge and hermeneutic sensitivity, but also locating it within the distinct modes of knowledge production and transmission, and perhaps a willingness to accept 'foundational hierarchical premises of nondemocratic worldviews' as they are (Jenco 2007: 744). The emphasis on cultural distance also informs the cosmopolitan method advocated by Farah Godrej, in which the theorist first adopts the language and cultural experience associated with the intellectual and lived tradition of the text, then tries to articulate its meanings to an audience that has not undergone these existential and experiential transformations (Godrej 2011). Godrej's cosmopolitan method develops Dallmayr's dialogic approach, which similarly calls for a comparative method that entails experiential transformation and an ability to write from the lived experience of more than one tradition (Dallmayr 1999, 2004). 
The emphasis on cultural difference can serve to highlight the ways in which non-Western thought can potentially extend or displace Western political theory in ethical and epistemological terms. In many cases, considerable linguistic, theoretic and ethnographic skills are required for immersion in a different tradition and the translation of its resources for Western audiences. The main pitfalls for advocates of the distancing approach involve how to avoid reinstating an East-West chasm under a different guise. The attempt to step outside Western concepts and categories poses two challenges. One is empirical: given historical crosscultural engagement, a strong separation between so-called Western and non-Western traditions is implausible (for a response, see Godrej 2011: 14). The second is the theoretical corollary to the first: the commitment to working within a tradition reifies the boundary of the tradition a priori.

In fact, the tension between resemblance and difference is a productive tension for CPT. Instead of treating this as a problem that needs to be resolved or transcended, a fruitful stance is to treat it as a necessary quality of the field. The tension is productive methodologically because it reminds us to self-reflect on the concepts, categories and norms that define our epistemological perspective. The tension also offers multiple intellectual contexts for the reconstruction of political thought.

In both normative-analytic and historical CPT discussed thus far, the practice of comparative political thought has focused overwhelmingly on key thinkers, exemplary texts and elite intellectual traditions (see also Thomas 2010). This has served to challenge the Eurocentrism of political theory in important respects, demonstrating, for instance, that Asia, Africa, the Middle East and Latin America have produced thought that matches Western thought in terms of its sophistication and creative power, and has the capacity to extend its moral and political scope. A key substantive contribution of these approaches has been to bring metaphysics back to the study of political thought (Goto-Jones 2011). CPT scholarship demonstrates that political and metaphysical questions pursued in separate domains in post-Enlightenment thought are deeply intertwined.

Nevertheless, the focus on semi-autonomous traditions and key thinkers underestimates the field's potential to expand the frontiers of mainstream political theory. In the next two sections we outline two approaches that go beyond the traditional preoccupation of political theorists with individual thinkers and elite traditions, to engage with how these are inhabited by people in their lived practices. Whereas normative-analytic approaches and historical approaches have tended thus far to emphasize 'non-Western' sources, as well as the Western and non-Western dichotomy as the telling axis of comparison (for an 
exception, see Goto-Jones 2011), the other two approaches seek to break down that dichotomous construction of 'comparison' and the focus on 'traditions' that has often accompanied this.

\subsection{Interpretive CPT}

Interpretive theorists challenge the view shared by the other approaches, that the primary purpose of political theory is normative or prescriptive, that of advancing visions of the right or the good (Freeden and Vincent 2013). Instead, in interpretive social science writings, the politicaltheoretic task of conceptual reconstruction serves also to theorize realworld political processes, and to advance explanations of political outcomes (Bevir and Rhodes 2002; Bajpai 2011). Interpretive social science approaches have often been conflated with historical approaches, but these are distinct. Interpretive theorists use social scientific methods qualitative data and qualitative methods of analysis (see Yanow and Schwartz-Shea 2013) - to provide detailed empirical accounts of meanings and 'thick description', to use Geertz's well-known term (Geertz 1973; Taylor 1985). Data sources can include constitutional and policy debates, interviews, participant observation, focus groups and ethnography. Methods of analysis can include discourse analyses of elite and colloquial texts (Bajpai 2011; Tripp 2013), as well as political ethnographies (Mahmood 2005; Wedeen 2008).

Like historical CPT scholars, interpretive social scientists too seek to reconstruct the meanings of ideas in particular contexts - what democracy, social justice, civil society mean to people in particular times and places. However, there are important differences with historical approaches. First, in interpretive CPT, the focus is not on the thought of exemplary thinkers or 'innovating ideologists' (Bajpai 2011), on the appreciation of the theoretical and political creativity of individuals such as Qutb or Gandhi. Instead, interpretive social scientists focus on what Lisa Wedeen terms meaning-making practices - discursive, rhetorical and performative. Practices pertain to what agents do, and how this interacts with language and other symbolic systems (Wedeen 2002: 714). Thought practices and meaning construction are not pursued here in the form of the ideas, beliefs or writings of individuals, as is common in historical approaches, but, rather, as embedded and framed within collective actions, both everyday and extraordinary (e.g. of compliance or protest) as characteristic of anthropological writings (Mahmood 2005; Wedeen 2008). For instance, Charles Tripp's account of ideas of political participation in the Middle East is based more on their articulation in repertoires of collective action and protest than on the 
writings of individuals (Tripp 2013). Tripp distinguishes conceptions of participation that derive from different types of political struggles - for a nation-state against Western rule, for 'dimuqratiyyat al-khubs [democracy of bread]' through direct action and occupation of public spaces, and for the preservation of an Islamic community through 'observance of the shari'a' (Tripp 2013: 91, 95-7). Humeira Iqtidar's account of shifts in Islamist political imaginaries in Pakistan goes beyond the focus on founding ideologues such as Maududi, to examine the narratives of ordinary activists and supporters of the Jama'at-e-Islami engaged in social and humanitarian work (Iqtidar 2011).

Second, interpretive CPT can be explanatory in ways that are distinct from historical CPT. Historians of political thought have also engaged explanation, but usually in terms of explicating why ideas assumed the form that they did at a given historical moment. Occasionally, links are posited between ideas and political outcomes. For instance, Roxanne Euben's study of Sayyid Qutb pursues a 'deeper, richer, fuller account of Islamist ideas', also because demonstrating 'the intellectual coherence and depth of fundamentalist ideas makes explanations of Islamic fundamentalism more causally adequate' (1999: 156). However, in most historical approaches, the further task of identifying and establishing such links between thought and action in specific contexts remains unaddressed. By contrast, in many instances of interpretive CPT, the reconstruction of thought focusses directly on improving explanations of particular political phenomena. How are religio-political identities (e.g. being Muslim, Hindu) produced, and why do these gain salience in certain contexts, and not others? How is political compliance produced, and why do 'some political ideologies, policies, and self-policing strategies work better than others'? How do actors' perceptions of what 'democracy' and 'religion' mean affect political outcomes (Wedeen 2002: 714)? For instance, Rochana Bajpai's account of conceptions of secularism, social justice, democracy, national unity and development in India based on the practices of political argument in constitutional and legislative debates seeks to delineate the distinctive features of these concepts in India, and also to improve explanations of policies of minority rights and affirmative action at critical junctures (Bajpai 2011).

Ideational explanation here has two elements. First, our explanations of political outcomes are necessarily incomplete without a grasp of the normative resources available to actors, just as they would be without knowledge of other resources - economic, institutional - available to them (Bajpai 2011). Here, ideas or norms can serve as an explanatory variable. For example, Matthew Nelson has shown how the shift from 
custom to shari'ah radically altered the pattern of local politics in Pakistan (Nelson 2011). Second, ideational practices (e.g. debates in institutional as well as non-institutional fora) serve as a lens for viewing political processes, for gaining better descriptions and thereby explanations of political change, in particular of shifts in relations of power (Asad 1993; Wedeen 2002: 714). For instance, the centralization of power in a polity at a given historical moment and its decentralization at another are manifested not necessarily, or only in the nature of party competition, but also in patterns of political argument, which a conceptual analysis of policy discourse reveals (Bajpai 2011).

Interpretive approaches have the potential to advance CPT in important respects. First, the focus on practices as the units of analysis opens up the category of 'tradition', which has often privileged elite sources and reinforced cultural boundaries. It offers the prospect of more nuanced assessments of similarity and difference across different traditions, and over time within a tradition. Second, interpretive CPT approaches typically focus on the present, bringing attention to bear on the recent political experience of Asia, Africa, the Middle East and Latin America that has remained relatively neglected in historical and normative CPT thus far. Third, interpretive CPT extends the role of political theory in political science, specifically in relation to ideational explanations of political outcomes, which remain underdeveloped in social science scholarship (see Bajpai and Brown 2013).

Nevertheless, one potential problem with interpretive approaches is that in expanding the role of CPT to include political explanation that is conventionally associated with political science, it risks losing what is distinctive in political theory. Its advocates reply that using the tools of political theory to conceptualize and theorize political phenomena and processes enhances the real-world relevance of political theory. This latter interpretation is in keeping with the historical emergence of the discipline in which political theory served as the reflective dimension of political science, helping the field define its questions and concepts (Wolin 1969; Gunnell 2010). Furthermore, within political theory, engagement with empirical politics on the part of political theorists is a growing trend. Here, the task of political theory is not seen just in terms of providing solutions to our current moral predicaments, but also as clarifying what these are, in helping give 'form to emergent realities that otherwise remain beyond our ken' (cf. Wolin 1969; Isaac 1995; Kaufman-Osborn 2010: 668 ), and thereby relocating political theory within the realm of political science (Freeden 2007; Gunnell 2010). 


\subsection{Critical CPT}

In the Marxist tradition of political theory, critical CPT connects to the 'struggles and wishes of the age' (Marx 1967). Critical CPT identifies the dissenting strands within elite traditions of political theory and the nonelite voices within the lived experience of political thought. Methodologically, critical CPT is the study of elite and non-elite actors, of canonical and non-mainstream texts, of texts and the actions and aspirations of those in struggle. Some of these actors can be marginalized in global politics or by local politics in struggles with elites. Globally and locally, marginalization differs whether due to race, religion, ethnonationality, language, sexuality or perceived sexuality.

Christine Keating situates her argument about the meaning of the social contract in the context of the decolonization of India (Keating 2011). Luis Cabrera locates his argument about global citizenship in the actions of global migrants, citizens policing the borders and those engaged in humanitarian aid in the borderlands (Cabrera 2010). Brooke Ackerly draws on the insights of women's rights activists from around the world to articulate a theory of human rights from the practice of struggle for rights (Ackerly 2008). Kim places his argument about Confucian democracy and law in the context of contemporary South Korea politics over the meaning of democracy and freedom (Kim 2014).

Sometimes called grounded political theory, these approaches are quintessentially question-driven inquiry, framing their questions around the political struggles of non-elites, that is, those who are not privileged in their contemporary political contexts. This approach seeks to broaden the history of ideas at stake in the political struggle to include not just the ideas of the winners, but also of those who struggled for a different political practice. The actions and aspirations of those in struggle are treated as text on a par with the texts inherited by elites. It also treats activists as political theorists (Cabrera 2010; Keating 2011: 114), and applies the insights gained by studying the struggles in one context (India) to the struggles in another (Keating 2011), to make more general claims about specific concepts and their use (Ackerly 2008; Beltrán 2009; Cabrera 2010), and to challenge familiar conceptualizations.

While critical, this view entails a general claim: that it is the study of ideas and concepts that are revealed in the struggles of politics, not just in the ideas and concepts that emerge victorious from those struggles. Certain substantive universals may emerge from such inquiry. But these claims proceed with a sceptical scrutiny for the potential to false essentialisms, false universalisms and exclusions. These can be made through the intent to include or broaden the perspectives being considered. At their best, 
critical grounded approaches to CPT work in alliance with non-elites in political struggle; this is a methodological alliance for understanding the struggle, not an ideological alliance of researcher and political actors.

One interesting potential problem with critical approaches is that they can be mired in discursive politics. If these politics get disassociated from the underlying problem or used to silence or deny the voice of some participants in the struggle (Mackey 2005; Rothschild, Long and Fried 2005; Fricker 2007; Medina 2012), then critical CPT does not lead to political or theoretical insights more fruitful than the more elite-textbased historical approaches to CPT. The critical grounded approach requires either an empirical component or triangulation across comparative methods.

Finally, critical CPT approaches use normative, historical and interpretive methods. What distinguishes critical CPT is its authors' normative commitment to those contemporary political struggles. In the following section, we turn to the discussion of methods - specific tools that multiple methodologies may use to effect the author's goals.

\section{How to Do CPT}

In a CPT project, as in other subfields of politics, methodologies and methods need to be chosen with respect to a particular question. CPT scholars often use a mixed methodology, perhaps beginning in one methodology and revising using another. In this light, it is best to think of the four CPT methodologies as providing an initial guiding framework. As with empirical social science, triangulation across methodologies and methods can be more fruitful than relying on one. The key to avoiding the potential for epistemological imperialism in political theory is to be question-driven, attentive to methodological pluralism even if your own methods tend towards one strand of the field, attentive to the potential of any method to be self-centric due to the building blocks of scholarship, and self-reflective about the best execution of the methods of your selected approach or approaches. These are 'meta-methods' if you will. Many, maybe even all of these, are or should be part of any political theory practice. Post-colonial, feminist and other critical approaches have made similar arguments. Nevertheless, we offer a CPT perspective on research practices and outline their concrete instantiation in CPT scholarship.

(a) Start with your research question rather than methodology or method. Several scholars have called for more question-driven research, in contrast with the emphasis on methods and models in political theory and political science (on the general point, see Isaac 1995; 
Shapiro 2005). CPT joins calls in the discipline for putting the question before methods. It has the potential to enlarge research questions beyond those traditionally addressed by political theorists to include those informed by deep engagement with non-Western sources on the one hand, and empirical social science on the other.

As with other forms of political theory, a CPT question can be based on an empirical observation. These can be empirical problems (such as violence, immigration, climate change, gender oppression and poverty) that pose challenges for how we live together. Such an empirical problem can also lead to a theoretical problem that needs to be addressed before we can think about how we might address the empirical problem (and others like it). As we saw earlier, CPT scholars have addressed questions of governance, human rights, democracy and citizenship. A CPT question can also come from a new way of reading a text that comes from the reading of texts in and/or across traditions. In sum, a CPT question can be grounded in a problem (e.g. poverty), a concept (e.g. human rights) or texts (e.g. Confucian and Neo-Confucian texts). Be aware of the fact that your question will influence your methodological commitments.

(b) Know your ontological perspective and be open to its revision. By your selection of a research project, you reveal to yourself and the world the ontological perspective behind the inquiry. Some differences among theorists can be ontological, but manifest themselves methodologically. For example, Andrew March argues that the important differences across historical traditions lie in the differences in their worldviews. In fact, March has a worldview (an ontological perspective) about the differences in worldviews. By contrast, Roxanne Euben argues that by familiarizing ourselves with seeming differences in worldviews, we can gain better self-understanding and an appreciation that differences are not as different as we might have thought. She has an ontological perspective on the inter-comparability and inter-compatibility of worldviews. In Enemy in the Mirror, she argues that 'Qutb's work must be understood as a "dialectical response" to rationalism and Westernization', and that he is 'participating in a conversation that we, as Western students of politics, not only recognize, but in which we participate' (Euben 1999: 155).

Consider the ways in which the tensions among competing readings or interpretations and seeming 'discontinuities' or irreconcilable differences across time and geography reveal not just intra-disciplinary methodological disagreements, but ontological differences. If you are doing CPT well, you challenge yourself to revisit your ontological perspectives throughout the research process. 
(c) Know your methodology and be open to its development. Question-driven research is in principle methodologically plural at the moment of inquiry. None of the methodologies discussed earlier requires that you use just one method. Each exemplifies a particular combination of methods. For instance, Euben in the example cited previously also uses interpretive and critical methods to some extent when she situates her reading of Qutb in the context of contemporary politics of his reception by Sunni and Western audiences.

Likewise, the same method can be used across methodologies. For example, historical and interpretive social scientists use textual analysis; however, interpretivists usually try to supplement this 'with more ethnographic modes of analysis (interviews, observation, etc.) so as to give more widespread accounts of the beliefs found among the different actors involved in a practice'. ${ }^{2}$

In choosing your methodology, ask yourself what your main purpose in undertaking CPT is. Is it the retrieval or recuperation of particular nonWestern thinkers or debates? If so, historical methodologies are likely to be most appropriate. Is it to respond to contemporary challenges that affect people across the globe (e.g. climate change) from the standpoint of the experience of those most vulnerable in Asia and Africa? If so, critical or normative methodologies are likely to be more suitable. Alternatively, your main interest may be the conceptualization and theorization of new forms of political action among elites and/or subalterns in Asia, Africa or the Middle East, for which interpretive CPT methodologies are likely to be most useful. Each methodology embodies a particular priority among the methods it deploys in order to resolve conflicts and ascertain the validity of conclusions.

(d) Know which methods you will need and be open to multiple methods. Consider the possible methods and select the right combination for your question. As with other areas of research, in CPT the use of multiple methods across different methodologies has yielded rich insights.

For example, conceptual analysis is typically used in analytic methodologies to construct normative arguments (see Olsthoorn's chapter in this volume and the discussion of the normative-analytic approach earlier), including arguments about the possible kinds of desirable political change (Angle 2005; Kim 2014). However, it can also be used in interpretive $\mathrm{CPT}$, where conceptual reconstruction serves to advance explanations of political outcomes and political change (e.g. Bajpai 2011). Interpretive CPT offers an interstitial space between political

\footnotetext{
${ }^{2}$ Mark Bevir, personal communication, May 2015.
} 
theory and political science, where the tools of political theorists are used for improving social science explanations.

Critical comparative political theorists have analysed non-elite texts and even treated as texts the arguments that are embedded in the political actions of non-elites who are seeking alternative political arrangements. Critical CPT methods include observation of contemporary struggles (Beltrán 2009; Cabrera 2010; Clifford 2012; Forman and Cruz forthcoming), critical rereading of historical struggles (Keating 2011) and even interviews with actors in the struggle (Ackerly 2008). Sungmoon Kim's Confucian Democracy in East Asia utilizes historical, interpretive and critical methods and normative-analytic argument in setting out the import of his project (Kim 2014).

Be aware that the findings from different methods may conflict. Methodological location and triangulation (see later) can help with the resolution of such conflicts.

(e) Be aware of your own boundaries. It is important to recognize that as a comparative political theorist, you both construct and deconstruct boundaries as you work. Attentiveness to that construction and reconstruction is a feature of CPT best practice.

Consider, for example, the political and theoretical debate in the 1990s about 'Asian Values' and their (in)commensurability with political equality, individual freedom and rights. In the Asian Values debate, some participants emphasized the distinctiveness of East Asian cultures (Zakaria 1994; Bell 2000). Drawing on textual analysis and cross-cultural comparison, they developed a reified dichotomy between Western and Asian traditions. Participants in that same debate challenged those readings of historical texts and offered competing interpretations of 'the' cultural tradition (Kim Dae 1994; Chan 1997). The debate revealed great differences within each of these intellectual and cultural groupings. The diversity within those broad civilizational categories - and their political import for charting possible ways of thinking about what ethical responsibility requires in the face of contemporary challenges - is obfuscated by the overgeneralized characterization of and sharp delineation between the dialogue partners.

(f) Acquire requisite language skills. CPT methods typically, but not necessarily, require competency in the language of the texts. Depending on the research question, the availability and quality of translations and knowledge about the politics and epistemology of a text's translators, some CPT can be done without fluency.

(g) Read texts closely and contextualize these. All CPT makes use of close textual reading. Whether your reading is typical or a nuanced rereading, be attentive to alternative readings of the texts (see also Blau's chapter in this volume). Debates from the time period, contemporary 
secondary literature and political history of the context can enhance the reading. Whereas the focus in reading texts is often the substance of their arguments, CPT scholars can also read texts for their insights into how to do political theory (e.g. Jenco 2007).

(h) Consider the broad range of available sources. When your research question relates to broad categories - such as culture or religion contextualize your account of any particular text or other evidence with reference to a broad range of sources. Remember (or reconsider) your ontological commitments when you identify your sources.

From a critical CPT perspective, it is especially important for you to consider the status of the authors of your texts at the time and in history. Much CPT broadens our sources, but you may not be able to include non-elite sources, those either lost to time because they did not generate texts that are available today or omitted because their texts are not considered 'theory.'

For example, in East Meets West, Daniel Bell broadens what counts as a text for political theory by taking the political ideas of two leaders in the Asian Values debate of the 1990s and articulating their views in the form of fictionalized characters. However, the fictionalized protagonists of the dialogue that he constructs between East and West are as elite as the political leaders on whose ideas the text is based (Bell 2000). Neither protagonist is engaged in a struggle for recognition and enjoyment of his own human rights. This is a critical CPT assessment of Bell's sources.

(i) Pick your qualitative methods carefully. Political practice can be a source of CPT 'text' for analysis. Michael Freeden, in his call for explicit methods for CPT, urges theorists to focus more on 'real world forms of political thinking' rather than great thinkers and texts that are unrepresentative of their contexts (2007: 2; see also Bajpai 2011). Godrej (2011) calls on CPT work to be anthropological or ethnographic. However, such work can also be qualitative without being ethnographic. For example, Ackerly (2001) looks at the human rights practices of activists to complement what they say about their work. Cabrera (2010) looks at the actions of migrants and those near and crossing borders.

Be aware too that textual and written sources also encode practices and ritual forms - the latter are not just to be found in the realm of 'behaviour'.

(j) Attend to sources of bias. A narrow source list can be one source of bias, but there are others. Because each methodological approach has strengths and weaknesses, be attentive to and make explicit the biases in your framing of the comparative project. For instance, does it frame Islamic, Indian or Chinese traditions in terms of their orthodox variants, or even their dominant heterodox strands? What alternative sources provide a counter-reading of the thinkers and traditions that are its focus? 
Have you constructed a dichotomous juxtaposition of two readings of a text? Are there others whose nuance is lost by your heuristic? In what ways are your empirical sources limited or limiting?

(k) Triangulate. Even if you use only one methodological approach, use your awareness of the other methodologies to create a reflective dialogue with yourself about the possible other approaches to studying your question. Consider other approaches. What would the approach consider or recommend, why is it tempting, and why is it less suited your question? Following Goodin's advice in this volume, show your work. The standard of showing your work is more detailed in a booklength treatment. However, the excuse of space for not treating a serious criticism or alternative reading is not intellectually satisfying. Space constraints may justify not pursuing a mixed methodology approach, but again, it is a weak response to not reflecting on the insights such an approach might offer your project.

(l) Consider co-authorship. Given the specialization of debates within political theory, the voluminous scholarship on the Middle East, Asia, Africa and Latin America, not to speak of the desired linguistic skills, serious comparative work requires considerable time and effort. Furthermore, as we have discussed and demonstrated in our coauthorship of this chapter, behind all CPT methodologies is an epistemological commitment to broadening the scope of insights that are brought to bear on a question. No matter your skills, the scale of comparative work and the scope of insight can be broadened through coauthorship.

(m) Be humble. When writing from a position of privilege, and most political theorists do, humility vis-à-vis what you can know is appropriate. Many of the 'how-to' points make reference to limitations, such as limited access to historical knowledge, disproportionate access to elite texts and limited access to the lived politics of those in struggle. In addition, use humility to reflect on the privileges of being able to do this work and the intellectual obligations of this privilege.

\section{Conclusions}

In the twenty-first century, the field of political theory and comparative political thought is global, not in the sense that any articulation of the complex web of concepts would be globally agreed to or that such agreement should be the goal, but rather that our interlocutors in this endeavour are not predetermined by our training, experience, geography or imagination, but may come from any place, time or family of inquiry. 
CPT can help us do political theory better. The field's internal discussions of methodologies and method can help its practitioners - novice and experienced - do their work better. One day the modifier 'comparative' will become associated with this time in the historical development of our discipline because in fact what we learn from how we do comparative inquiry improves how we do political theory (Dallmayr 2004; Euben 2006: see especially chapter 2; March 2009: 536-7; see also Leader Maynard's chapter in this volume). CPT enables us to deepen our reflections about what we mean by 'we' when 'we' as theorists engage in an ethical and political reflection.

Political, economic and social empirical problems with normative import are the important questions for political theorists. Because many of these recur, the history of political thought is a likely source for a wealth of reflective insights. Because these issues have been relevant in the world and over time, the historical intellectual traditions that may provide insight may come from anywhere. Because these issues are pressing now, contemporary theorists around the world should draw on each other's reflective insights in order to broaden our understanding of the web of relevant concepts and help clarify our articulations of them. The vastness of these ambitions extends beyond the capacity of any individual's life work. Therefore, political theory relevant to the significant challenges posed by these ambitious normative puzzles needs to be a collaborative enterprise. Taken together, the range of methodological forms that CPT takes enables political theory to ever improve its contributions to the study and practice of politics.

CPT methods build a shared, though not necessarily common platform across multiple domains of knowledge production. They challenge false universalisms and dominant Western stereotypes. They situate political theory in multiple contexts of resemblance and difference and expand the notion of text to include debates and action. CPT is one of the subfields in political theory that engages in constructive criticism of the ways in which political theory can perform global politics, not just write about it. CPT methods push political theory to become increasingly self-aware about that possibility.

\section{Acknowledgements}

We are grateful to participants in the London Comparative Political Thought seminar, and to Adrian Blau, Humeira Iqtidar, Leigh Jenco, Sungmoon Kim and Tejas Parasher for their comments on earlier versions. 


\section{References}

Ackerly, Brooke, 2001. 'Women's human rights activists as cross-cultural theorists', International Feminist Fournal of Politics 3, 311-46.

Ackerly, Brooke, 2005. 'Is liberalism the only way toward democracy? Confucianism and democracy', Political Theory 33, 547-76.

Ackerly, Brooke, 2008. Universal Human Rights in a World of Difference. Cambridge University Press.

Ackerly, Brooke and Jacqui True, 2010. Doing Feminist Research in Political and Social Science. Palgrave Macmillan.

Ackerly, Brooke and Jacqui True, 2012. 'Methods and methodologies', in Georgina Waylen, Karen Celis, Johanna Kantola and Laurel Weldon, eds., The Oxford Handbook of Gender and Politics. Oxford University Press, 109-33.

Angle, Stephen, 2002. Human Rights and Chinese Thought: A Cross-cultural Inquiry. Cambridge University Press.

Angle, Stephen, 2005. 'Decent democratic centralism', Political Theory 33, 518-46.

Angle, Stephen, 2012. Contemporary Confucian Political Philosophy. Cambridge: Polity.

Asad Talal, 1993. Genealogies of Religion: Discipline and Reasons of Power in Christianity and Islam. Baltimore, MD: Johns Hopkins University Press.

Bajpai, Rochana, 2002. 'The conceptual vocabularies of secularism and minority rights in India', Fournal of Political Ideologies 7, 179-97.

Bajpai, Rochana, 2011. Debating Difference: Group Rights and Liberal Democracy in India. Oxford University Press.

Bajpai, Rochana, 2012. 'Liberalisms in India: a sketch', in Ben Jackson and Marc Stears, eds., Liberalism as Ideology: Essays in Honour of Michael Freeden. Oxford University Press, 53-76.

Bajpai, Rochana and Graham Brown, 2013. 'From ideas to hegemony: ideational change and affirmative action policy in Malaysia, 1955-2010', fournal of Political Ideologies 18, 257-80.

Bell, Daniel, 2000. East Meets West: Human Rights and Democracy in East Asia. Princeton, NJ: Princeton University Press.

Bell, Daniel, 2006. Beyond Liberal Democracy: Political Thinking for an East Asian Context. Princeton, NJ: Princeton University Press.

Bell, Daniel, 2008. China's New Confucianism: Politics and Everyday Life in a Changing Society. Princeton, NJ: Princeton University Press.

Beltrán, Cristina, 2009. 'Going public', Political Theory 37, 595-622.

Bevir, Mark and R. A. W. Rhodes, 2002. 'Interpretive theory', in David Marsh and Gerry Stoker, eds., Theory and Methods in Political Science. Basingstoke: Palgrave, 131-52.

Browers, Michaelle, 2006. Democracy and Civil Society in Arab Political Thought: Transcultural Possibilities. Syracuse University Press.

Cabrera, Luis, 2010. The Practice of Global Citizenship. Cambridge University Press.

Chan, Joseph Cho Wai, 1997. 'An alternative view', fournal of Democracy 8, 35-48. 
Chan, Joseph Cho Wai, 2009. 'Is there a Confucian perspective on social justice?', in Takashi Shogimen and Cary Nederman, eds., Western Political Thought in Dialogue with Asia. Lanham, MD: Lexington Books, 261-77.

Chan, Joseph Cho Wai, 2015. Confucian Perfectionism: A Political Philosophy for Modern Times. Princeton, NJ: Princeton University Press.

Clifford, Stacy, 2012. 'Making disability public in deliberative democracy', Contemporary Political Theory 11, 211-28.

Dallmayr, Fred, ed., 1999. Border Crossings: Toward a Comparative Political Theory. Lanham, MD: Lexington Books.

Dallmayr, Fred, 2004. 'Beyond monologue: for a comparative political theory', Perspectives on Politics 2, 249-57.

Euben, Roxanne Leslie, 1999. Enemy in the Mirror: Islamic Fundamentalism and the Limits of Modern Rationalism. Princeton, NJ: Princeton University Press.

Euben, Roxanne Leslie, 2006. Fourneys to the Other Shore: Muslim and Western Travelers in Search of Knowledge. Princeton, NJ: Princeton University Press.

Forman, Fonna and Teddy Cruz, forthcoming. 'Global justice at the municipal scale: the case of Medellín, Colombia', in Thomas Pogge and Luis Cabrera, eds., Institutional Cosmopolitanism. Oxford University Press.

Forst, Rainer, 2001. 'Towards a critical theory of transnational justice', Metaphilosophy 32, 160-79.

Freeden, Michael, 1996. Ideologies and Political Theory: A Conceptual Approach. Oxford: Clarendon Press.

Freeden, Michael, 2007. 'The comparative study of political thinking', fournal of Political Ideologies 12, 1-9.

Freeden, Michael and Andrew Vincent, eds., 2013. Comparative Political Thought: Theorizing Practices. New York: Routledge.

Fricker, Miranda, 2007. Epistemic Injustice: Power and the Ethics of Knowing. Oxford University Press.

Fukuyama, Francis, 1992. The End of History and the Last Man. New York: Free Press.

Gaus, Gerald, 1990. Value and Fustification: The Foundations of Liberal Theory. Cambridge University Press.

Geertz, Clifford, 1973. The Interpretation of Cultures: Selected Essays. New York: Basic Books.

Godrej, Farah, 2011. Cosmopolitan Political Thought: Method, Practice, Discipline. Oxford University Press.

Gordon, Jane Anna, 2014. Creolizing Political Theory: Reading Rousseau through Fanon. Bronx: Fordham University Press.

Goto-Jones, Chris, 2011. 'A cosmos beyond space and area studies: toward comparative political thought as political thought', boundary $238,87-118$.

Gunnell, John, 2010. 'Professing political theory', Political Research Quarterly 63, 674-79.

Herzog, Don, 1985. Without Foundations: Fustification in Political Theory. Ithaca, NY: Cornell University Press.

Huntington, Samuel, 1996. The Clash of Civilizations and the Remaking of World Order. New York: Simon \& Schuster. 
Iqtidar, Humeira, 2011 'Secularism beyond the state: the "state" and the "market" in Islamist imagination', Modern Asian Studies 45, 535-64.

Isaac, Jeffrey, 1995. 'The strange silence of political theory', Political Theory 23, 636-52.

Jenco, Leigh, 2007. "WWat does heaven ever say?” A methods-centered approach to cross-cultural engagement', American Political Science Review 101, 741-55.

Jenco, Leigh, 2011. 'Recentering political theory: the promise of mobile locality', Cultural Critique 79, 27-59.

Kaufman-Osborn, Timothy, 2010. 'Political theory as profession and as subfield?', Political Research Quarterly 63, 655-73.

Keating, Christine, 2011. Decolonizing Democracy: Transforming the Social Contract in India. Pennsylvania State University Press.

Kim Dae, Jung, 1994. 'Is culture destiny: the myth of Asia's anti-democratic values', Foreign Affairs 73.

Kim, Sungmoon, 2014. Confucian Democracy in East Asia: Theory and Practice. Cambridge University Press.

Laborde, Cécile, 2008. Critical Republicanism: The Hijab Controversy and Political Philosophy. Oxford University Press.

Mackey, Eva, 2005. 'Universal rights in conflict: "backlash" and "benevolent resistance” to indigenous land rights', Anthropology Today 21, 14-20.

Mahmood, Saba, 2005. Politics of Piety: The Islamic Revival and the Feminist Subject. Princeton, NJ: Princeton University Press.

March, Andrew, 2009. 'What is comparative political theory?', The Review of Politics 71, 531-65.

Marx, Karl, 1967. Writings of the Young Marx on Philosophy and Society, ed. Loyd David Easton and Kurt Guddat. Garden City, NY: Doubleday.

Medina, José, 2012. The Epistemology of Resistance: Gender and Racial Oppression, Epistemic Injustice, and Resistant Imaginations. Oxford University Press.

Mills, Charles, 2015. 'Decolonizing Western political philosophy', New Political Science 37, 1-24.

Nelson, Matthew, 2011. In the Shadow of Shari, ah: Islam, Islamic Law, and Democracy in Pakistan. Columbia University Press.

Parel, Anthony, 2006. Gandhi's Philosophy and the Quest for Harmony. Cambridge University Press.

Rothschild, Cynthia, Scott Long and Susana Fried, eds., 2005. Written Out: How Sexuality Is Used to Attack Women's Organizing. New York: International Gay and Lesbian Human Rights Commission \& The Center for Women's Global Leadership.

Shapiro, Ian, 2005. The Flight from Reality in the Human Sciences. Princeton University Press.

Tan, Sor-Hoon, 2003. Confucian Democracy: A Deweyan Reconstruction. Albany: State University of New York Press.

Taylor, Charles, 1985. Philosophy and the Human Sciences. Cambridge University Press.

Thomas, Megan, 2010. 'Orientalism and comparative political theory', The Review of Politics 72, 653-77. 
Tripp, Charles, 2013. 'Acting and acting out: conceptions of political participation in the Middle East', in Michael Freeden and Andrew Vincent, eds., Comparative Political Thought: Theorizing Practices. New York: Routledge, 88-109.

Von Vacano, Diego, 2015. 'The scope of comparative political theory', Annual Review of Political Science 18, 465-80.

Wedeen, Lisa, 2002. 'Conceptualizing culture: possibilities for political science', American Political Science Review 96, 713-28.

Wedeen, Lisa, 2008. Peripheral Visions: Publics, Power, and Performance in Yemen. University of Chicago Press.

Whitehead, Laurence, 2013. 'Latin American approaches to "the political"', in Michael Freeden and Andrew Vincent, eds., Comparative Political Thought: Theorizing Practices. New York: Routledge, 40-59.

Wolin, Sheldon, 1969. 'Political theory as a vocation', American Political Science Review 63, 1062-82.

Yanow, Dvora and Peregrine Schwartz-Shea, eds., 2013. Interpretation and Method: Empirical Research Methods and the Interpretive Turn. Armonk, NY: M. E. Sharpe.

Zakaria, Fareed, 1994. 'Culture is destiny: a conversation with Lee Kuan Yew', Foreign Affairs 73, 109-26. 